\title{
ANALOGÍAS ICONOGRÁFCAS: A PROPÓSITO DE ANDRÉS SERRANO Y SU OBRA "POLÍTICAMENTE INCORRECTA"
}

\author{
ANALOGIES ICONOGRÁFCAS: A PURPOSE OF ANDRES \\ SERRANO AND HIS WORK "POLITICALLY INCORRECT"
}

\author{
Fernando Martín Martín \\ Unviersidad de Sevilla, España
}

El Presente artículo tiene como objetivo el analizar iconográficamente e iconológicamente , la obra del fotógrafo Andrés Serrano, estableciendo Paralelismos con las Artes Plásticas del Pasado y del Presente, Ofreciendo nuevas consideraciones interpretativas sobre sus temas más representativos.

Palabras Clave: Artes Plásticas, Provocación, Fotógrafa, Retrato y Religión

This artcle reeks to make an iconographic and iconologycal analisis of tre work of photographies Andrés Serrano, paralells witht visual arts of past and present, ofering new interpretve considerations their most prominent themes.

Keywords Visual arts, Provocatve, Photographies, portrait and Religion

Soy una especie de disidente, no soy blanco, no soy negro, no soy gay, no soy ni esto ni aquello... no estoy adscrito a ningún grupo que se vaya a sentr afectado.

Andrés Serrano

Nacido en la ciudad de Nueva York en el año de 1950, Andrés Serrano es uno de los fotógrafos actuales más conocidos y a la vez controvertidos, como consecuencia entre otros motivos, por abordar ciertos temas cuyos argumentos provocan airadas reacciones, siendo su nombre sinónimo de subversión e indigesto, sobre todo a partir de su famosa obra "Piss Christ" 1987. Hijo de madre cubana y padre hondureño, mulato y de religión católica, su infancia no fue muy afortunada, de hecho no tuvo contacto con su padre, encontrándose casi siempre 
ausente de Honduras, de ahí que afirmase no conocerle y recordar su vida familiar como un "estgma".

Desde muy temprano mostró inclinaciones artísticas, concretamente hacia la Pintura, entrando a los diecisiete años en el Brookling Museum School, donde permaneció hasta 1969. Aunque sus primeras incursiones las hace en el campo de la pintura, fue gracias a una amiga cuando empezó a tener sus primeros contactos con la fotógrafa que sustituiría definitivamente en 1981, tres años después, realiza sus primeros trabajos fotográficos en blanco y negro sobre escenas callejeras y paisajes. Desde un principio concibe su obra en series monográficas sobre temas determinados, siendo precisamente la serie" Bodily Fluids" (Fluidos corporales) con la que se dio a conocer, un comienzo que nació bajo el signo del escándalo, debido a la exhibición entre otras fotógrafas de la mencionada "Piss Christ", convertida desde entonces en una referencia en su trayectoria de heterodoxia y blasfemia, semejante, pero en el orden escatológico, a la célebre "Merda de artista" (Mierda de Artsta) 1961, de Piero Manzoni. Residente habitual en Nueva York, Serrano es un artsta cosmopolita que ha vivido y viajado por diversas razones de trabajo en muchos países, teniendo un amplio historial expositivo internacional, tanto en galerías privadas como en museos, así como su participación en ferias y bienales².

Inscrito en la posmodernidad cultural y social propia de la década de los ochenta, años marcados por el puritanismo de Reagan, la catástrofe de Chernóbil o la pandemia del sida, entre otros eventos históricos, desde el punto de vista artístico y dentro de eclecticismo propio del momento, en el que emergen movimientos como los relacionados con el tema de género, políticas de identidad, apropiacionismo, la utilización del cuerpo como metáfora del dolor y el placer, destacando sobre todo las nuevas práctcas fotográficas, las cuales experimentan un renacimiento y protagonismo inédito hasta entonces, llegando su punto álgido de desarrollo en los años noventa, años estos últimos donde también el denominado "Arte Abyecto", adquiere categoría estética y estatuto de

${ }^{1}$ A.A.V.V.: Andrés Serrano. A History of sex. Cat. Museum Groninger. Groninger, 1977. Maria Otamendi: “Andres Serrano autoretrato en primer plano". Rev. Lápiz nº 124. Madrid, 1996, p. 3. Rosa Olivares: "Esto no se mira, esto no se toca, esto no se dice". Rev. Exit $\mathrm{n}^{\circ} 8$, Madrid, 2002.

${ }^{2}$ Su primera exposición individual tene lugar en 1985 en Leonard Perslson Gallery de Nueva York. En 1990 expone en Tokio en The Seibu Museum of Art, para seis años después, en 1996 hacerlo en The New Museum of Contemporany de Nueva York en calidad de retrospectiva: Andrés Serrano 1983-1993. En España expone habitualmente la Galería Juana de Aizpuru desde 1997. En 2006 el centro de Arte Contemporáneo Artum de Vitoria, le dedico una importante muestra bajo el título Andrés Serrano: el dedo en la llaga. 2006. Que con posterioridad se presentaría en la Sala Tecla de Hospitalet de Llobregat, el Museo Iberoamericano de Badajoz. Este mismo año participó en Photo España Festival, Madrid. 
tendencia. Artistas como Robert Mapplephorpe, Diana Arbus, Cindy Sherman, Ricki Smith, Mc Carthey, Joel Peter Witkin, entre otros, así como la mayoría de los partcipantes en la famosa exposición organizada por el magnate y coleccionista Charles Saatchi "Sensación” en la Real Academia de Londres, en 1997, certifican bien esta última práctica ${ }^{3}$.

Como gran parte de los autores que utilizan la cámara como medio de expresión, la fotografía del neoyorquino, paralelamente a su visión subjetiva de las personas y de las cosas, posee un componente biográfico importante, así, su formación católica es fundamental para comprender las series dedicadas a la religión, del mismo modo que su admiración por el barroco, especialmente la pintura que dejará huella en ciertas composiciones e iconografías. Por otra parte, no debe pasarse por alto que Andrés Serrano, aún habiendo nacido en Estados Unidos, posee una herencia afrocubana que está presente en su quehacer, como ocurre con otros artistas procedentes del mundo hispano y que emigraron a Nueva York, como es el caso, por ejemplo, de Jean Michael Baskiat (1960-1988), hijo de un contable haitiano y madre puertorriqueña, sin olvidar aquellos que salieron de sus respectivos países para ubicarse sobre todo en la ciudad de los rascacielos, dadas las mayores posibilidades que ofrecían para su desarrollo artístico, existiendo en la actualidad un importante colectivo de artistas plásticos iberoamericanos con representación en instituciones culturales y museos estadounidenses ${ }^{4}$.

"Yo trato de hacer una obra para el próximo siglo"... "Soy como una Marca, me paseo por muchos sitos, pero nunca me quedo"... "Quiero hacer algo que produzca una sacudida"... "No tengo una actitud moralizante, porque todo es posible, eso lo aprendí de Duchamp"... "trabajo sobre el lado oscuro de la humanidad, pero desde la oscuridad, no desde la maldad o la subversión" ${ }^{5}$.

Estas declaraciones dicen mucho sobre la personalidad de Andrés Serrano, denotando una actitud creativa que han logrado un consenso unánime sobre su

${ }^{3}$ MARÍN GORDILLO, Elizabeth: Como triunfar en el mundo del arte. (Estrategias del joven arte de los '90. CAAC Málaga, 2007. ALIAGA, Juan Vicente: Bajo vientre. Representaciones de la sexualidad en la cultura y en el arte contemporáneo. Dirección Bellas Arte, Valencia, 1997.

${ }^{4}$ Es bastante explicito como síntoma de recepción y valoración del arte Hispano, el hecho de que Alfred Baar al fundar el emblemático MOMA (1929) neoyorkino, incluyese tempranamente en sus colecciones autores iberoamericanos, algo que en Europa tardaría bastantes años en hacerse y ya esto en la posguerra. En la actualidad Estados Unidos cuenta con varias instituciones dedicadas a la creatividad hispana, estando presente en: Museo de Latinoamérica de L.A. Museo de Barrio de Nueva York, donde se organizan importantes exposiciones del arte "chicano", El MULAA de Arte Norteamericano de Long Beach, California, sin olvidar, las colecciones del Whitney o el Esmisorian American Arte en Washington, o el Museum American Art de la Universidad de Texas, Houston, entre otros

${ }^{5}$ Op. Cit. María Otamendi. p. 36-37 
trabajo, donde es imposible mantenerse indiferente ante lo que hace. Evaluar su obra como una estética de la transgresión es un ejercicio reduccionista, que si bien su producción tiene un indudable carácter desafiante, no todo responde a esa premisa extrema, como lo ejemplifican series como "Nómadas" o "América" . Quehacer plástico que responde siempre a una necesidad sincera de dar respuesta a lo que siente y quiere hacer, Un reto alejado siempre de lo convencional, que parece seguir la máxima Ezra Pound, "Haz que sea Nuevo", como gusta de repetir este excelente fotógrafo.

Un estudio pormenorizado sobre sus imágenes nos lleva a definir su trabajo como síntesis entre lo documental y lo simbólico, una doble naturaleza donde testimonio y arte convergen centrados en la figura humana, a la cual retrata y percibe desde ángulos y situaciones distintas, que nos informan sobre el individuo, como protagonistas de una representación relacionada con la soledad, la miseria, el poder, la religión, la muerte o el sexo, con el fin primordial de proporcionar verdades visualmente construidas sobre la sociedad y la condición humana por muy perturbadoras que sean.

Técnicamente sus fotografías se caracterizan por no sufrir retoques ni manipulación en el laboratorio, limitándose a un proceso de ampliación de formato dependiendo de la serie, obras realizadas en estudio, siendo sus modelos por lo común, personas anónimas encontradas en la calle cuya personalidad ha despertado el interés del artsta como acontece con "Nómadas" (Nomads), otras por el contrario, son fruto de una elección preconcebida: "Morgue" o "Historias del Sexo" (A history of Sex), donde hay una puesta en escena de la dramaturgia representada. Fotografías muy clásicas en su concepción formal, encuadre, tratamiento lumínico, revelándose en ocasiones la deuda contraída para con la pintura clásica, así como con los medios de comunicación. Obras donde el argumento por sobrecogedor y violento que sea no carece sin embargo de atracción y de belleza, aunque ésta, sea una belleza convulsa e incluso siniestra.

A estas alturas de los tempos, casi, o nada, está por decir o hacer en el mundo del arte, todo parece responder a un "deja vu" universal, ya Ernest Gombrish, nos recordaba que "En arte no hay sorpresas, sino simples cambios de propósitos". Si ello lo aplicamos al arte moderno, es decir, a las vanguardias históricas, y lo cotejamos con el arte producido desde finales de los sesenta a la actualidad, plena era posmoderna, la percepción de que todo posee referencias, se confirma de manera clara, existiendo coincidencias y paralelismos donde la diferencia no estriba en la forma, sino en la intencionalidad y el modo de crearla plásticamente. En este sentido, lo que podemos considerar como "Estética de la transgresión", posee un largo historial manifestado sobre todo durante la primera mitad del siglo $\mathrm{XX}$, con algunos precedentes de obras individuales en la trayectoria de algunos artistas como lo fueron "El origen del mundo"1866 Courbet o el "Desayuno en la hierba" 1863 Manet, ambos en el Museo d' Orssay, dos ejemplo referenciales que en su día suscitaron la repulsa y la crítica más hostil, especialmente la segunda, 
dado que la polémica obra de Courbet, consecuencia de un encargo particular específico, su conocimiento visual tardaría aun bastantes años en ver la luz. ${ }^{6}$

No obstante es durante el desarrollo de los distintos movimientos de vanguardia, en su posición y actitud contestataria frente a las normas y la estética establecida por la academia, cuando desde el punto de vista formal, iconográfico y lingüístico, se producen acciones y obras que constituyen claros precedentes efectuados en las últimas décadas, siendo sin duda el dadaísmo y su consustancial actitud nihilista y provocadora, además del surrealismo revolucionario, donde la conexión con relaciones de autores contemporáneos se hace más evidente, como es notorio en ciertas obras de Andrés Serrano, sin obviar el hecho de que el fotógrafo neoyorquino desde la subjetividad y máxima libertad creativa, como otros muchos artistas recicla y relee la profusión de imágenes que los medios de comunicación y la historia ofrecen continuamente.

Serrano, como otros artistas de su generación y época, en alguno de sus trabajos envuelve "detritus en celofán", con imágenes de formalidad atractiva y ejecución perfecta, sin que por ello, sus argumentos dejen de ser repulsivos, obscenos o desagradables. Luzbel, el ángel más hermoso creado por Dios, Lucifer, portador de luz, al pasar a la condición de "ángel caído", no perdió su inteligencia ni poder, sino que éstos las pondrá al servicio del mal.

El fotógrafo, nos muestra la condición humana, su naturaleza variable en todos sus registros, una realidad que viene de ella misma, pese que a veces sea infame y siniestra, o los deseos ocultos y la imaginación, de esa facultad incontrolada de la que dijera André Bretón, "que no perdona", ni esta sometida a ninguna censura, sea moral o social, pero existe, aunque sea "políticamente" incorrecta.

\section{“CABEZA DE VACA” 1984 (Figura 1)}

Como si se tratara de un trofeo de caza, dispuesto sobre elegante peana de mármol para una exhibición cinegética, se muestra una cercenada cabeza de vaca vista de perfil. La blancura pilosa de la testa del bóvido plasmada con gran realismo, contrasta con las huellas sanguinolentas del cuello, a la vez que un ojo abierto parece mirarnos suscitando una inquietante reacción. Imagen que nos

${ }^{6}$ El origen del mundo, como la célebre Fuente de Duchamp, se conoció durante años por reproducción, así como la obra del autor del Gran Vidrio, gracias a la fotografía de Alfred Steglitz y las réplicas que posteriormente se han hecho, pues la original después de provocar la indignación de la exposición del Salón de los Independientes de Nueva york de 1917, Duchamp la retiró a la vez que presentaba la dimisión de la selección de la que formaba parte. La original se perdió. Sobre el cuadro de Courbet véase Thierry Sabater.: El Origen del Mundo. Historia de un cuadro de Gustav

Courbet. Edit Trea, Gijón, 2009. A.A.V.V.: Nueva York y el arte moderno Alfred Stglitz y su mundo Nueva York 1905-1930 . Cat. Reina Sofa, Madrid, 2005. 
recuerda las impresionantes fotógrafas del escritor Eli Lotar sobre el matadero parisino de la Villete ilustrando el artículo " Massacre" del ensayista y disidente surrealista George Bataille para la revista "Documents", en cuyo texto se dice entre otras cosas: "La víctimas ... no son los matarifes de los animales, sino los buenos ciudadanos que han llegado al punto de no poder soportar más que su propia fealdad, fealdad que responde en efecto, a una necesidad enfermiza de limpieza, de pequeñez biliosa y de aburrimiento ${ }^{7}$.

"Cabeza de vaca " es una obra de sus comienzos como fotógrafo profesional, auténtica naturaleza muerta, cuya primera lectura hace pensar en el género clásico del bodegón tan cultivado en la pintura en su afán mimético de representar el esplendor de animales cazados para el fogón y la buena mesa, algo que tiene sus excepciones, como es el emblemático "Buey desollado" de Rembrand 1655 , Museo del Louvre, cuya imagen de voluptuoso sacrificio promueve otras asociaciones ajenas a la recreación y el despertar de los sentidos. Por otra parte, una apreciación más cruda, cruel y violenta, es fácil asociarla si tenemos la experiencia de asistir al "espectáculo" del sacrificio de animales en el matadero tal como hizo en su día Eli Lotar, o paseamos por algunas carnicerías del mercado, donde pendiendo de un garfio, aparecen las descarnadas cabezas y cuerpos de los animales inertes

\section{“PISS CHRIST" 1985 (Figura 2)}

La figura de Cristo crucificado como objeto de profanación posee un historial iconográfico no pequeño, baste rememorar los dibujos de Felicien Rops en su singular versión de las "Tribulaciones de San Antonio", 1870, aunque ciertamente ha sido el arte moderno y actual, cuando ha proliferado en un contexto de permisividad absoluta, cuando cualquier tema por delicado y escabroso que sea, será abordado sin reparo y escrúpulo. Repasando las obras de esa naturaleza transgresora, probablemente "Piss Christ" haya sido el icono que ha producido un mayor escándalo y reacción, a la par, como se advirtió anteriormente, la que dio a conocer y se asocia a su autor en los medios artísticos. Un crucifijo de plástico es sumergido en orina. El tema pertenece a los trabajos sobre religión que desde muy temprano el artista mostró interés, obra ésta incluida en la serie de los "Fluidos", que tiene como material o sustancia elementos corporales orgánicos, como leche, sangre, orín o semen, utilizados como alternativa o experimentación estética, cuyos resultados cromáticos y texturales se muestran a veces afines con la pintura, cuestión esta que siempre ha atraído al autor, de hecho, en varias ocasiones se ha declarado "Un pintor que usa la cámara". La indagación con

${ }^{7}$ George Bataille: “ Abatoir” en Rev. Documents, nº6, París, 1929, p.32. A.A.V.V.: La subversión de las imágenes. Surrealismo. Fotografía. Cine. Fundación Mapfre, Madrid, 2010, p.265-267 
fluidos corporales, ha hecho que como se ha producido en otras obras del mismo periodo, que contienen sangre o leche- "Cruz de sangre", "Cruz de leche 1985", se consiguen efectos visuales de carácter pictórico y abstracto, algo apreciable en "Piss Christ", al ofrecer una impresión difusa y empañada que envuelve la figura, otorgándole un cierto misterio e inconcreción ${ }^{8}$.

Conocido sobre todo como fotógrafo, Man Ray es en realidad un artista polifacético cuya permanente inquietud investigadora hizo de él uno de los creadores más fértiles de la vanguardia. Pintor, fotógrafo, diseñador, cineasta ... su militancia en el dadaísmo primero - cofundador con su amigo Duchamp de este ismo en Nueva York- y más tarde, su adhesión al surrealismo, dieron como resultado la realización de obras referenciales, como su sádico "Regalo"1921 (Plancha con clavos). En este contexto de instrumental sardiano, el artista norteamericano hace su particular "Homenaje a Sade" 1923, al "divino Marqués" como gustaba referirse Bretón al autor de Justine. El inventor del rayograma, toma la imagen del trasero de una mujer de nalgas voluminosas superponiéndole una cruz invertida, creando una representación irreverente a partir del símbolo por antonomasia del cristianismo. Con posterioridad, Man Ray volvería a retomar la figura de Sade, tanto en pintura, "Retrato imaginario de Sade" 1938, Menil Collecton Houston (Texas) como en escultura, la cual se inspira en ésta, interpretando el rostro del aristócrata petrificado, en alusión a su reclusión en la fortaleza de la Bastilla donde permaneció preso bastantes años ${ }^{9}$.

Surrealistas como el poeta Paul Eluart, o pintores como Salvador Dalí -frontispicio de Inmaculada Concepción, 1930 del autor aludido- o el propio Luis Buñuel en la "L'âge d'or" 1930, utilizan la cruz de una forma sacrílega, así en su último fotograma de la película, los supervivientes de una criminal orgia guiados por el duque de Blangis, al salir del castillo de Selliny, se encontrarán con una

8 "Piss Christ" escandalizo dos años después de su realización, es decir, a partir de 1987 en que fue incluido en la Bienal de Whtney Museum de Nueva York, con posterioridad y durante su exhibición en el Museo de Arte Contemporáneo de Avignon, Francia, fue objeto de un nuevo atentado en 2011, siendo destruida. La utilización de la imagen de la imagen del crucifijo ha sido objeto de numerosos trabajos por parte de artstas contemporáneos, así como otros símbolos religiosos León Ferrari, La civilización Occidental y Cristana, 1966; Cueto Lominchar, La pasión de Rebeca, 1998; Sarah Lucas, "Christo,Usted sabe que no es fácil" (realizado a partir de cigarrillos) 2003; o Demian Hirst, "Mi nombre es Humano", 2006 (donde la imagen de Cristo es sustituida por un cordero desollado), entre otros. Mario Meyer.: De persona a persona en Man Ray: Yo soy un enigma. Fundación Picasso, Málaga, 2006 p. 17-32. Op. Cit. La subversión ... p.102-108

9 Véase Marcel Jean : Historie de la pinture surrealiste. Edit Seuil. París, 1999. A.A.V.V.: Cosas del surrealismo. Surrealismo y diseño. Cat. Gougenheim, Bilbao, 2008. 
cruz clavada en la nieve con los cabellos de las mujeres que ellos mismos habían $\operatorname{asesinado}^{10}$.

\section{“TRAYECTORIA DE EYACULACIÓN” 1987 (Figura 3)}

Obra no menos impactante y perteneciente de igual modo a la serie Fluidos corporales, es "Trayectoria de eyaculación", título que responde literalmente y de forma real, al registro fotográfico del itinerario trazado por el esperma en el aire. Representación de carácter viscoso y abstracto, cuya imagen recuerda, y nunca mejor dicho, a la conformación nebulosa de estrellas poéticamente conocida como vía láctea.

El uso del semen, como la sangre, de plural simbología- lujuria, renacimiento, vida etc, está presente en varias obras de Serrano, como se ha señalado. Entre sus antecedentes se encuentran dos ejemplos emblemáticos de la vanguardia histórica: "Paisaje culpable" 1946 de Duchamp, Museo de arte moderno de Toyana (Japón) y con anterioridad "Onan" 1934 de Dalí11.

Fiel a su idea de que la simple elección de un objeto por parte del artista es equivalente a creación, expresada en sus famosos "Ready made" Duchamp, haciendo realidad una vez más su papel de anticipador de algunos de los movimientos surgidos después de la década de los sesenta, realiza "Paisaje culpable" , pudiéndose inscribir por un lado de modo indirecto en lo que se conoce como "body Art" como su famosa "Cabeza con estrella cometa"1931, y por otro, dentro de la genealogía de creaciones eróticas como "Hoja de vid hembra " 1950 , "Objeto dado" 1951, y "Cuña de castidad" 1954, sin olvidar la instalación de "Etant Donnés", 1946-1966 Museo de Philadelphia.

De modo semejante a Serrano, es su utilización de materia orgánica, "falso culpable" es una pequeña composición de formato cuadrado y sobre superficie de hule, en la que se ha vertido semen, creando una imagen abstracta de contornos expansivos, que resalta sobre un fondo oscuro ${ }^{12}$.

${ }^{10}$ Luis Buñuel.: Un perro andaluz. La edad de Oro. (Guiones) Edit. Era, México, 1971. P.163-164

${ }^{11}$ La representación onanista o masturbación, tene abundantes precedentes iconográficos, pero es en la modernidad cuando de manera más explicita y realista aparece. A modo de ejemplo ilustratvo recuérdese la imagen de "Dos jóvenes burlándose de un hombre", perteneciente a las pinturas negras de Goya, 1820. Obras más próximas cronológicamente, unas, visualizando angustia y culpabilidad: "Autorretrato masturbándose" de Egon Schiele, Galería Albertna de Viena, 1911, otros más amables y placenteros Rodin, Klimt o Christan Schad, "Las amigas", Neue Natonal Gallery Berlin, 1928. Véase Sarane Alexandrian: Dalí et les poetes. Edit. Filipacchi, París, p. 7-9. A.A.V.V.: Vie publique de Salvador Dalí. Tomo II, Centro Pompidou, París, 1979, p.37

12 A.A.V.V.: Duchamp. sala de exposiciones de la Caja de pensiones, Madrid, 1984. Francisco Javier San Martn.: Dalí y Duchamp. Una fidelidad oculta. Edit. Alianza, 
Por su parte, Salvador Dalí cumpliendo el encargo de George Huget de ilustrar su libro de "Onan" publicado por ediciones surrealistas 1934, realiza una portada llena de grafismos a modo de tachaduras irregulares, como consecuencia de haber sido dibujadas compulsivamente y sincopadamente con una mano mientras que con la otra el pintor español, tan adepto a la masturbación, hacia lo propio. En cierta forma su representación recuerda a las aleatorias y automáticas composiciones de Jackson Pollock y sus conocidos goteos o drippings ${ }^{13}$.

\section{“ROOSVELT" 1990 (Figura 4)}

Con amplia tradición histórica, el retrato, ha sido siempre uno de los géneros más importantes, constituyéndose en un método de conocimiento sobre las personas tanto desde el punto de vista fisonómico como psicológico. El retrato dentro de la fotografía actual ocupa un lugar privilegiado. Andrés Serrano en su serie "Nómadas" iniciada en los noventa, alcanza una inestimable cualificación, ratificada años después con su otra serie titulada "América" 2003. "Nómadas" es una extraordinaria galería de personas anónimas captadas por las calles, parques, metros, soportales, etc... de la gran ciudad, representados como arquetpos sociales integrados por gentes marginales mendigos, vagabundos, desheredaos etc cuya personalidad queda refejada sobre todo en las miradas, miradas que trasmiten resignación, temor, tristeza, soledad desamparo etc... generalmente son retratos frontales y de media fgura, sin más identfcación que su concreción como individuo y su raza, universales en su condición "desclasada". Retratos que perteneciendo a la corriente naturalista, nos hace pensar a veces en los personajes tomados como modelo para sus composiciones religiosas o profanas por Caravaggio o José de Ribera, exentos de todo idealismo o signo de santdad, iconografas que como en el caso de Serrano, fueron extraídas de las calles de la Roma o Nápoles del XVII, poseyendo como único credencial su singularidad fsionómica. Del mismo modo podemos cotejar y traer aquí las fotografas del francés Pierre Gonnord en su excelente trabajo ttulado genéricamente "Realidades", con retratos con tanta verdad y belleza como "Ahmed", el emigrante argelino descubierto en un comedor social, cuya mirada es toda una declaración de su estado de soledad e indigencia, del que sólo conocemos el nombre. "La fotografa- nos dice Gonnord para mi es una forma de resolver las cosas. Una resistencia contra el olvido. Pero no el mío, sino el del otro, sobre el hombre en general"14.

Madrid, 2004. P.106-109.

13 A.A.V.V.: Vie publique de Salvador Dalí. Tomo I, Centro Pompidou, París, 1979.

${ }^{14}$ Mariano Navarro: "Entrevista", Realidades. Fotografas de Pierre Gonnord en el Museo de Bellas arte de Sevilla, Edit. Junta de andalucia, Sevilla, 2006, p.34 


\section{“KLAUSSMAN” 1990 (Figura 5)}

La representación del mal, de los grandes ttanes del imperio invisible, como ellos mismos se autodenominan, tene en la serie "KKK", correspondiente a la serie Ku Klux Klam, una de las secuencias fotográfcas de mayor relieve simbólico y estétco en el trabajo de Serrano. La tristemente conocida organización xenófoba, homofóbica y ultraderechista, cuya pertenencia a la sociedad estadounidense pese a no tener la infuencia y el poder de otros tempos, no por ello ha desaparecido, perviven en ciertos sectores de la población en nombre de la supremacía de la raza blanca y sus discutbles privilegios sobre los demás.

La forma de interpretar esta serie sobre la mencionada organización secreta, hace que su autor recoja fundamentalmente pormenores desde distntos ángulos, en el que predomina el plano medio o el detalle del personaje oculto tras su extravagante atuendo. Símbolo de intolerancia extrema, se nos informa en ocasiones, de su identidad jerárquica dentro de la organización a través de los diferentes emblemas en la vestimenta. Imágenes en el que se percibe como el tratamiento de los paños y pliegues de la vestimenta, se ha cuidado con especial esmero, que unido al contraste cromático de las distintas partes del atuendo, ofrecen unos resultados de gran calidad plástica.

En "La luz no llega..." del autor sevillano Agustín Israel Barrera, bajo una apariencia similar a la usada por los integrantes del "KKK" y contrapuesto a los encuadres cortos de Serrano, donde los paños en esta ocasión mojados y el capirote sirven de enmarcado para la figura humana que encarna una expresión del mal, bien distinta, una forma de ver el problema de la inmigración y la integración racial o religiosa, radicalmente opuesta a "Klausmann", usando hábitos penitenciales propios de la celebración de la Semana Santa, donde el carácter intolerante se denuncia en pro de la tolerancia y la integración. El autor nos dice refriéndose a la significación de su obra "Hasta los años noventa, la población española había sido relativamente homogénea cultural y étnicamente. Sin embargo, la llegada masiva de inmigrantes en los últimos años ha generado una mayor diversidad racial, cultural, religiosa y lingüística. Los inmigrantes del Magreb suelen intentar entrar en el territorio español usando pateras o cayucos, para cruzar el Estrecho de Gibraltar o a las islas Canarias, con el inconveniente de que a veces este trayecto se transforma de la gran esperanza e ilusión, al drama infernal de la muerte, las costas españolas están bañadas por la sangre y el sudor de esas personas, que no llegaron e intentaron ver en nuestro país una forma de vida mejor. La diversidad cultural y religiosa es cada vez más patente en España, pero la tragedia, la muerte, la desesperación o la esperanza, son iguales para todos, sea cual sea nuestra procedencia, tradición, cultura o creencia religiosa" $"$.

${ }^{15}$ A.A.V.V.: Fronteras de Papel, XII Certamen de creación Edit. Delegación de juventud y Deportes del Ayuntamiento de Sevilla, Sevilla Mayo 2009, p.34. 
“MUERTE POR AHOGAMIENTO” 1992 (Figura 6)

Con el nombre de "La Morgue" 1992, se identfca una de las series más sobrecogedoras e impactantes de cuantas ha realizado su autor. El argumento no es otro que la muerte, "su rostro", Muerte violenta, representada por personas anónimas en el depósito de cadáveres. Fisionomías en primer plano cuyas caras dejan entrever las huellas de su fallecimiento, sus causas-enfermedad, asesinato, accidente, etc-dando visibilidad al rigor morts- la deformación, la patétca mueca, el hematoma, la negrura producida por la quemadura etc... Otras veces, los rostros son susttuidos por otras partes del cuerpo, como manos, pies, brazos, fragmentos captados, con cortes, heridas.... Imágenes algunas que traen a la mente los estigmas representados en las iconografas religiosas de santos martrizados. "Para mí - nos dice Serrano- no son cadáveres, no eran cuerpos sin alma, senta la persona, la humanidad, aunque no tuviera la apariencia de cuando estaban vivos, siempre los traté como si estuviese delante de un ser humano"16.

La imagen de una persona muerta siempre conmociona e invita a la refexión, pero no todas producen el mismo sentmiento y emoción. Esto ocurre con la imagen de Laura Palmer (Shery Lee) la joven protagonista asesinada de la famosa serie televisiva "Twin Peacks" dirigida por el controvertdo y original David Lynch. $\mathrm{Su}$ rostro en primer plano ha pasado a convertrse en un icono de la muerte juvenil en la historia del cine. Contrariamente a los protagonistas de Serrano, la fisionomía de Laura no presenta signos de violencia, sus facciones y expresión son de serenidad, dando la sensación de estar dormida. Envuelta y enmarcada en plástico a modo de sudario, pese a tener el cabello revuelto y mojado, ofrece una extraña atracción contrastando la palidez de la cara, con el negro pelo y los labios violáceos, una tonalidad predominante en la composición. Esta representación de la muerte juvenil, trae el recuerdo del hermoso y dulce semblante de Elisabeth Sidal como modelo de "Ofelia" 1852 Tate Britsh Museum la obra maestra de John Ever Millais, y emblema iconográfico del movimiento prerrafaelista. Más acorde con las imágenes de "la morgue", y factible en su comparación, por su espeluznante crudeza es la estremecedora fotografía de Mat Collishat, "Agujero de bala", que formaba parte de la polémica muestra "Sensaciones" Una composición formada por quince cajas de luz con una dimensión de gran formato, ofrece en un primerísimo plano el orifcio ensangrentado producido por el impacto de una bala en la cabeza de una persona. Imagen propia de un archivo forense policial, que ejemplifica bien lo que Marga van Mechlem llama "El lado trasero del arte", el lado más oscuro de la condición y naturaleza humana, perteneciente a la tendencia de lo abyecto, como así mismo hiciera Cindy Sherman en su repulsiva serie "Rituales

\footnotetext{
${ }^{16}$ op. cit., María Otamendi, p. 34
} 
sexuales" 1992, cuyo argumento es la degradación, el excremento y la inmundicia en una convivencia de sexualidad perversa y patológica ${ }^{17}$.

\section{“ANTONIO Y ULRIKE” 1995 (Figura 7)}

Aunque la serie "Budapest", denominada así por ser en la capital húngara donde se realiza, posee un contenido explícitamente sexual, algunas obras como "Antonio y Ulrike", dada su representación entra dentro de la categoría erótica del desnudo. Se trata de un retrato doble, dos personas, un anciano y una joven desnudos, de él sólo se percibe el rostro apoyado en el pecho de ella dirigiéndole una mirada de ansiedad, mientras ella, por su parte lo hace hacia otro lado, con expresión seria y refexiva como si dudara de la relación con un hombre mayor. Una imagen que asociamos en su interpretación, al tema de la seducción, frecuente en la pintura del siglo XVI, como se puede apreciar en las distntas versiones, por ejemplo que hiciese Lucas Crannach, con el título "La cortesana y el hombre mayor". Sin embargo dejando aparte la semejanza en cuanto al sentdo y la relación de dos personas adultas de distinta edad, nuestro interés se centra más en el protagonismo de la mirada de la anciano, algo que nos retrotrae a enlazar la obra de Guirlandaio con "El Abuelo y el nieto", Museo del Louvre de Guirlandaio, donde el pintor renacentista con admirable maestría expresa dos sentimientos distintos que tienen en la mirada la esencia de la obra. Pese a no saber con certeza quienes son los personajes, con probabilidad pertenecen al círculo de la familia florentina Tornabuoni, para la cual entre otros, realizó el magnifico retrato de "Giovanna"1488 actualmente en el Museo Thyssen de Madrid. Con estilo preciso, casi fotográfico, dado el extraordinario realismo con el que esta resuelto, sobre todo la cabeza del anciano, sorprende por una parte la expresión de ternura conseguida del abuelo concentrada en la mirada hacia el nieto, a la que responde el infante con un ademán de abrazo, existiendo así mismo una complicidad en las miradas. Por otro lado sobresale la sabia captación de interés del niño en su atenta fijación en ese rostro y la llamativa protuberancia nasal de la dermatosis del anciano. Guirlandaio, como Serrano nos ofrece a su vez dos edades, plenitud y decadencia biológica.

${ }^{17}$ En realidad, la herida que se muestra en la serie fotográfica de Mat Collisham, está producida por un pinchahielos aunque su apariencia recuerde al impacto de una bala. Marga Van Machelen "Las excrecencias corporales en el arte" [en red] Signos el arte abyecto: htp: //fp.chasque.net/relación/9909/signos.htm [última consulta: 11/8/2012] Eva Respini, Johanna Bourton y John Water Sindy Sherman, MOMA, Nueva York, 2012. 
“KIOTO” 1996 (Figura 8)

Sexo y erotismo ocupan un capítulo fundamental en la producción y trayectoria de Serrano como se evidencia en distintas series, como la ya mencionada "Budapest" 1994, "Historia del sexo" 1996 o "Interpretación de los sueños" 2001. El sexo, como la religión o la muerte, son temas universales que casi siempre han sido objeto de controversia no dejando indiferente sus plurales interpretaciones, que van desde la versión amable y sensual, hasta la perversión y el horror. Todas, por lo demás basadas en una realidad que ha servido de inspiración a lo largo de la historia, existiendo abundantes ejemplos calificados dentro del concepto tabú. Las series de obras integradas bajo los títulos anteriormente citados, entran dentro de lo que se puede considerar "El lado oscuro del sexo", representaciones producto de obsesiones y deseos inconfesables, sean reales o ficticios, de ahí el repertorio de imágenes donde se explora y rebasa los límites de lo convencionalmente concebido como moral: escenas de dominación, zoofilia, felatio, bondage...sin excluir imágenes misóginas alegóricas al sexo femenino como símbolo de castración y dependencia del hombre: "Vaginas dentadas", 2001 obra esta, que tiene su correspondencia amable y humorística con la serie fotográfica realizada por la artista española Mireia Sents, bajo el ttulo genérico de "Joyas" 1987, compuesto de fotografías en blanco y negro, donde en primer plano el sexo masculino o femenino se convierte en exclusivo protagonista, a la manera de "estuche" o recipiente para perlas, sortijas, alfileres etc... lectura irónica y lúdica donde el cuerpo y todas sus parte anatómicas se convierten en soporte artístico y de reflexión ${ }^{18}$.

De forma extrema y afán al contexto sexual aludido, muchas de las fotografías de Serrano, guardan un estrecho paralelismo con otro de los autores de mayor controversia como es el japonés Araki, el cual representa a la mujer, -mujer oriental ataviada casi siempre con su vistoso y elegante atuendo tradicionalcomo objeto sexual en escenas sadomasoquistas. En este sentido son numerosas las imágenes de mujeres medio desnudas atadas con cuerdas siguiendo el arte denominado "Kimbaku" o de atadura erótica, obras por otra parte de gran perfección técnica e indudable estética ${ }^{19}$.

Referencias plásticas, como antecedente representativo sobre este tipo de sevicias, que representan a la mujer sujetas con ligaduras, es cita obligada el nombre de Hans Bellver y las fotografías de su célebre "Poupées", articuladas en las más diversas y convulsas posturas, teniendo así mismo su correspondencia real, con modelos: "Unie Atada" 1928. Tampoco, y dentro del mismo contexto de artistas de vanguardia, debemos olvidar a Man Ray y su "Venus restaurada" 1935,

${ }^{18}$ véase José Luis Gallero "Referencias” Mireia Sents. Fotografas, 1983, 2008, Círculo de Bellas Artes, Madrid, 2008. Pp 23-47

${ }^{19}$ Véase Araki Nobiyoshi: Araki Gold. Edit. Eskira Nueva York. 2008. 
en la que pese a su irónico posee el mismo sentido de los ejemplos anteriores, abordando desde la práctica del objeto surrealista - de funcionamiento simbólico-aquí, y como es habitual en su obra, tanto fotográfica como escultórica, sirviéndose del torso de una escultura clásica, iconografía, también muy recurrente en Giorgio de Chirico y sus metafísicas interpretaciones: "representaciones del poeta" $1913^{20}$.

\section{“GUIADA” 1996 (Figura 9)}

Es un bello retrato de una joven atractiva con abundante cabello que se derrama por sus desnudos hombros, su cabeza ladeada, dirige su mirada hacia arriba sobre algo que no percibimos, pero que por su expresión parece complacerle. Sedente, en un interior lleva un amplio y hermoso atuendo de seda, dejando ver una parte de su cuerpo descubierto, pendiendo de su cuello un collar. Esta fotografía perteneciente a la serie "Historias del sexo", del mismo modo que la comentada de "Antonio y Ulrike", por sus características representativas le hacen una obra autónoma y sin mucha relación con el resto del conjunto de la serie, dedicada fundamentalmente al sexo y teniendo como único elemento común el ser la misma modelo que ha posado en otras ocasiones.

Aunque la intencionalidad de su autor está lejos del personaje con el que la asociamos, a "Guida" su imagen nos evoca a la espléndida interpretación de "Magdalena penitente" de Caravaggio en la Galería Doria de Roma, una Magdalena actual y sin aura de identidad sacra, del mismo modo que la representada por el genial pintor.

Pocas figuras en la historia del cristianismo han tenido una más rica y variada iconografía que María Magdalena, por lo general representada espiando sus pecados de una anterior vida disoluta, apartada del medio urbano, sola y un paisaje árido, cuando no en una cueva a la manera de San Jerónimo. Caravaggio, siempre revolucionario y distinto en la interpretación de los personajes sagrados, no sólo toma como modelos a personas de la calle vulgares e indigentes, sino que además recrea de forma inédita a los personajes dándoles un carácter profano. En este sentido, si no se conoce la obra y sólo atendemos al título, puede conducir a engaño, asociando sus representaciones a la habitual iconografía de la santa purgando sus pecados. Contrariamente a esto, Caravaggio sitúa a Magdalena, sola en una estancia, como una cortesana ataviada con lujoso vestido, sentada, con las manos descansando sobre ampulosa capa, dormida.... agotada, por el cansancio causado por su innoble oficio de mujer pública, junto a ella, en el suelo se muestran esparcidos varios objetos que indican su condición, dinero, joyas, un frasco de perfume etc. Lo que hace especialmente sugestiva y fascinante esta imagen, es

${ }^{20}$ Sarane Alexandrian: "Anatomie de l'image” en Hans Bellmer, Filipacchi, París 19971, pp. 6-7, op. cit. La subversión de las imagenes... p. 113-119 
como el genio del naturalismo, ha sabido captar psicológicamente el estado de la santa, huyendo de toda aparatosidad para centrarse en la persona y su vulnerable condición humana.

\section{“MUJER Y NIÑO” 1996 (Figura 10)}

Como si se tratara de una Madonna con su hijo, Serrano nos muestra una maternidad, un retrato concebido frontalmente, tan frecuente en su fotografía, en el que representa a una mujer negra desnuda con un niño blanco entre sus brazos al que contempla con cariño. Fácilmente claro en el mensaje como alegato contra todo perjuicio racial, la imagen posee la fuerza estétca del contraste étnico de los protagonistas, a la vez de servir como medio de reflexión contra todo perjuicio y a favor de la tolerancia, especialmente hacia una sociedad como la estadounidense, donde en determinadas épocas del pasado, la mujer de color fue utilizada como nodriza, bien como carencia biológica sustitutiva de la madre, bien para salvaguardar su armonía corporal.

La fotografía tiene su correspondiente réplica en la obra de Oliviero Toscani y su innovadora y a la vez provocadora concepción artística. Sin duda el fotógrafo italiano marcó un antes y un después en el medio de la publicidad. Sus llamativas imágenes en gran tamaño ubicadas por las calles de muchas ciudades como reclamo al servicio de la conocida firma Beneton, consttuye una auténtica revolución al utilizar como mensajes icónicos, escenas y personajes que solicitaban nuestra mirada sobre problemas tan graves y tan propios de nuestros tempos, como el sida, la conciencia medioambiental, la guerra, el racismo etc... publicidad que no eximía tampoco, antes al contrario el escándalo desde el erotsmo y utilizando como medio la religión, recuérdese su conocida y célebre representación de un hombre vestdo de sacerdote besando a una mujer con hábitos ${ }^{21}$.

\section{“BELLO NOCK” 2003 (Figura 11)}

Desde mediados del siglo XIX pasado, EEUU se convirtió para muchos en la tierra de las oportunidades por excelencia, de ahí que en su calidad de país receptor, configurará una sociedad compleja y diversa en la que conviven numerosas razas, religiones y costumbres, procedentes de todo el planeta. Esta multiculturalidad social, concentrada sobre todo en las grandes ciudades, Nueva York, Los Ángeles Chicago, etc... se reveló como un magnifico campo de trabajo que Serrano aprovecha para escrutar la realidad humana creando una interesante radiografía de sus habitantes, trabajo que denominó "América "2003. En cierto modo, su autor a semejanza del gran fotógrafo August Sander durante la época de

\footnotetext{
${ }^{21}$ Véase Oliverio Tosacani: Adiós a la publicidad. Edit. Omega, Barcelona, 1996
} 
entreguerras en Alemania, nos da constancia a través de su escrutadora cámara, de ese caleidoscopio humano, sin distinción de raza, oficio o edad. Así, desde el" boy Scout" 2003, hasta la "Conejita del Play boy" 2002, se nos ofrece una extensa galería de personajes cuya apariencia física e indumentaria indican el papel que desempeñaron en la vida, sea el de un pope ruso ortodoxo, "Bishop Mercurius" 2002, el barbudo y circunspecto judío, "Leib kats" 2002, o la pequeña niña aspirante a Miss américa, "Jewel-joy-stevens” 2003. Recorrido en el que como es natural- pues forma parte integrante de la realidad social-, también tiene cabida el extravagante como el retrato de simpático joven "Bello Nock" con sus hirsuto y flameante cabello, que nos trae a la mente el trabajo de Pierre \& Gilles; esta pareja de artistas franceses, inscritos dentro de lo que pudiera concebirse como relecturas Kisch en clave pop, que nos deja también su particular crónica social desde el ángulo de la ironía y el humor, siendo los medios de comunicación, cine, música, prensa etc...con sus variopintos y curiosos personajes, su principal fuente de inspiración. Recreando las postales antiguas de souvenirs o las embelesadas imágenes de parejas de enamorados, enmarcados como si fuesen estampas del santoral, narran historias fantásticas recargadas y barrocas con colores intensos y brillantes, un buen ejemplo de lo descrito y de su desenfadada creatividad cotejable con la fotografía citada de Serrano, es el entrañable y risueño retrato juvenil del famoso y polifacético diseñador francés Jean Paul Gauter, al cual sitúa en el centro de una guirnalda de margaritas a la manera de tondo, portando el mismo un ramo de estas flores, subrayando el carácter idílico de la representación ${ }^{22}$.

Fecha de recepción: 30 de septiembre de 2014

Fecha de aceptación: 28 de noviembre de 2014

${ }^{22}$ Este tipo de trabajo ha ejercido una notable influencia en los medios publicitarios, así como en el área plástica, algo, esto último que puede cotejarse o asimilarse en cierta medida con la obra del tándem español "Los Costus" (Enrique Naya y Juan José Carrero). Véase Manuel Caballero y Eduardo Rodríguez.: Clausura (Costus). Diputación, Cádiz, 1992. Paul Ardenne.: Pierre Gilles: Double J. 1976-2002, Edit. Taschen, 2007. 


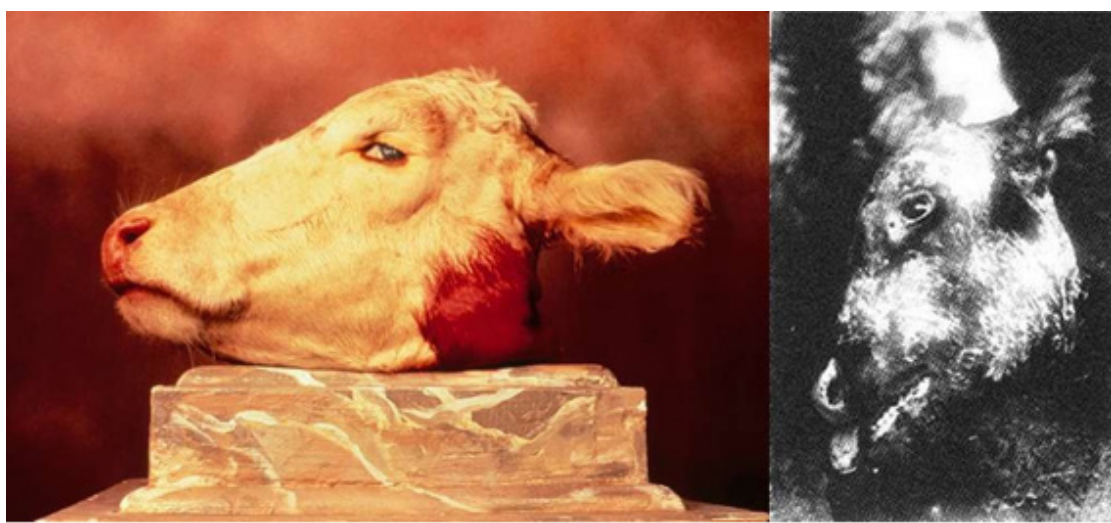

Figura 1. "Cabeza de vaca” 1984. "El matadero de la Villete de París” 1929 Eli Lotar.
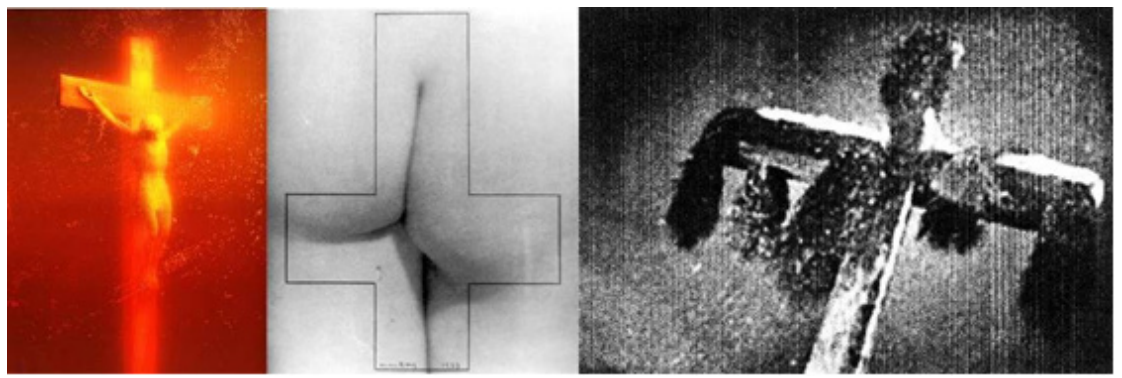

Figura 2. "Piss Christ" 1985. "Homenaje a Sade" 1933 Man Ray Fotograma "La edad de oro" Buñuel 1930.
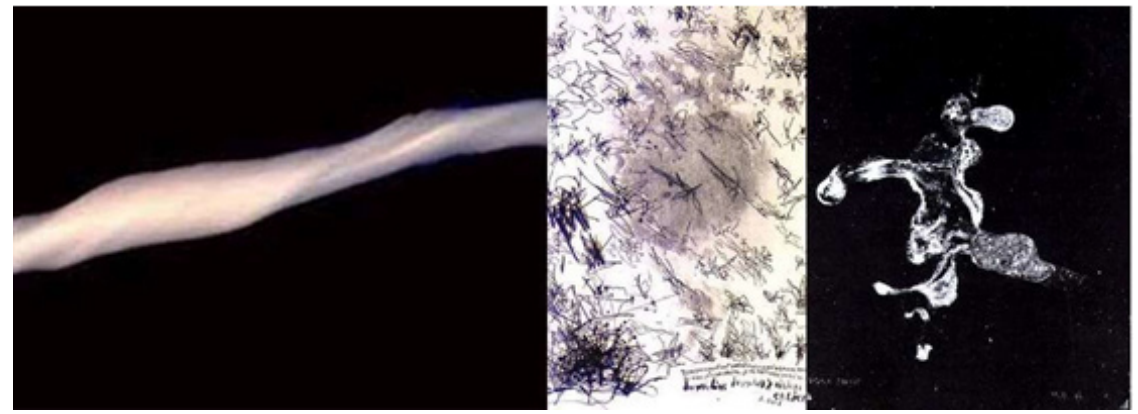

Figura 3. "Trayectoria de eyaculación” 1987. "Onan “1934 Salvador Dalí "Paisaje culpable" 1946 Marcell Duchamp. 


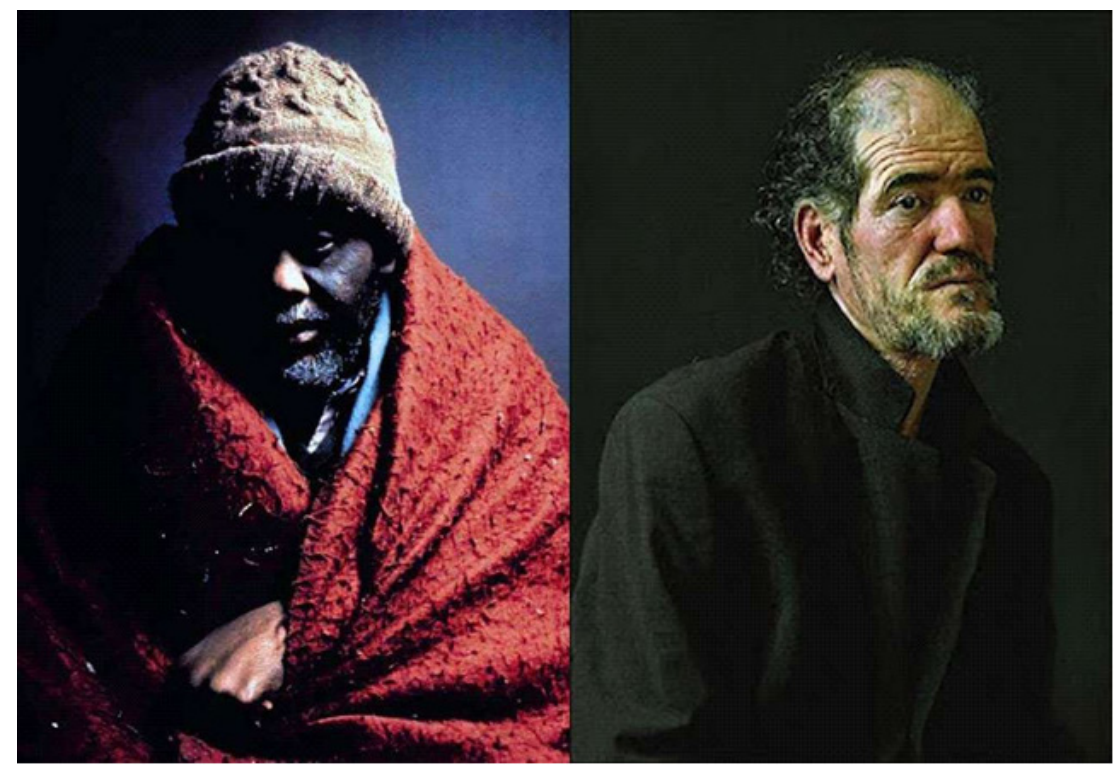

Figura 4. "Roosvelt"1990. "Ahmed” 2005 Pierre Gonnord.

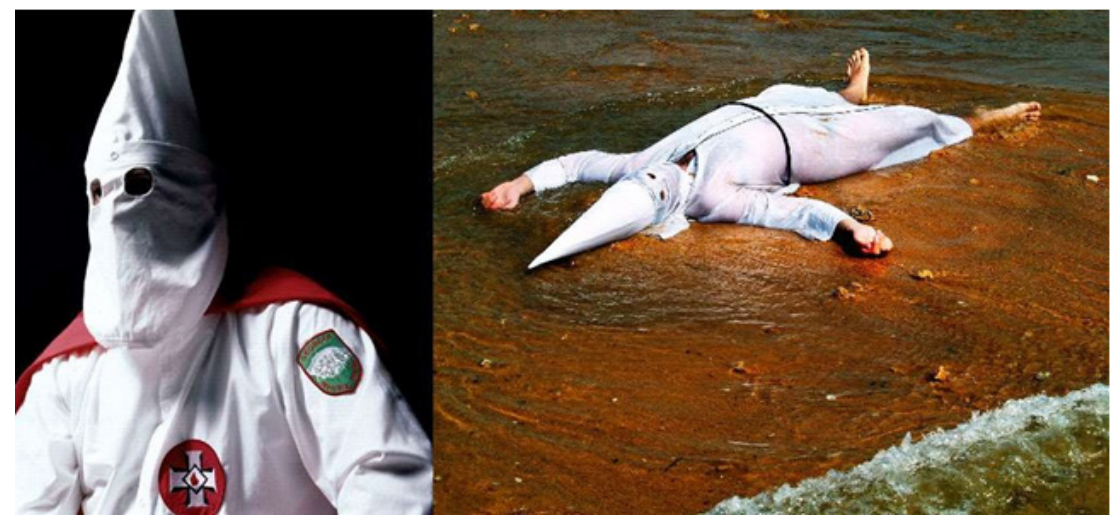

Figura 5. "Klaussman” 1990."La luz no Llega...” Agustn Israel Barrera 2009. 


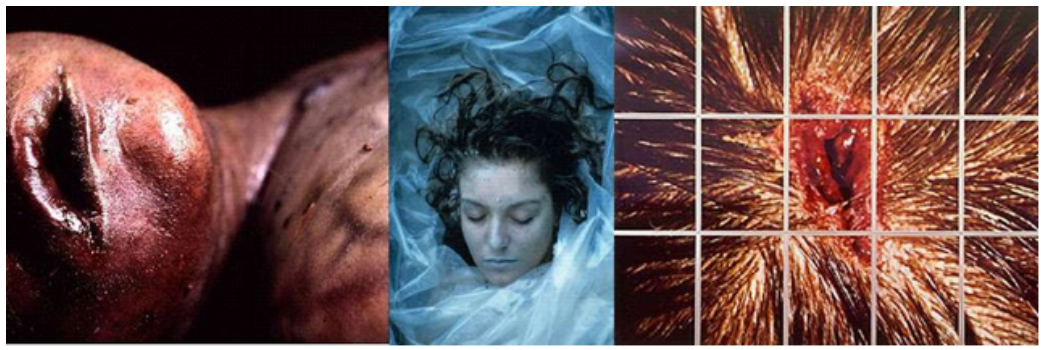

Figura 6."Muerte por ahogamiento" 1992 "Laura Palmer" en Twin Peacks de David Lynch 1989 "Agujero de bala" Mat Collishat.

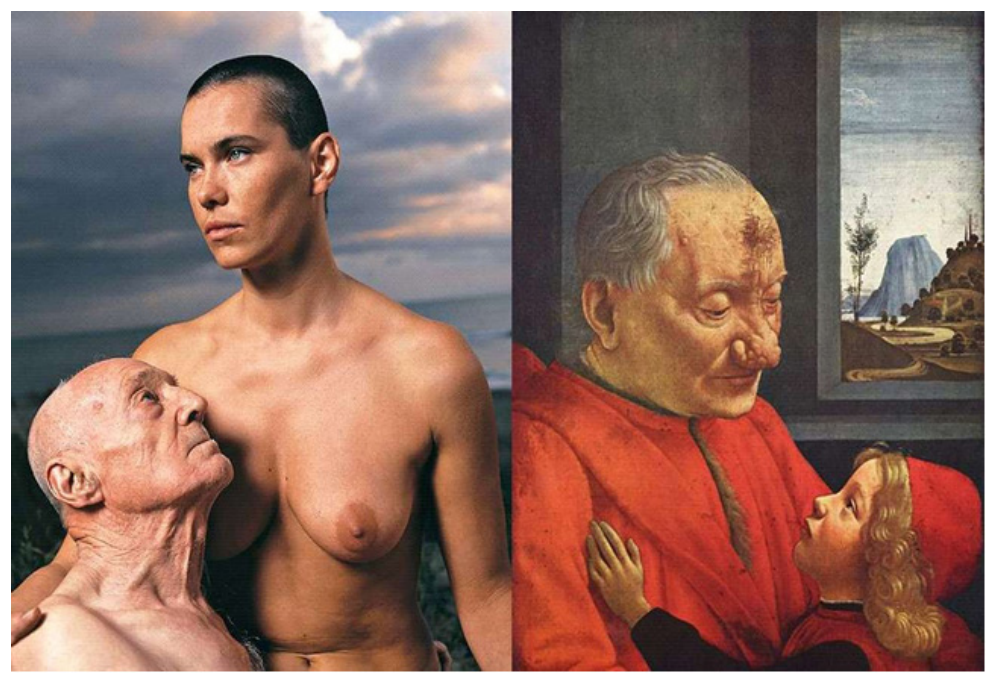

Figura 7."Antonio y Ulrike" 1995. "El Abuelo y el nieto" Domenico Guirlandaio" 1480.
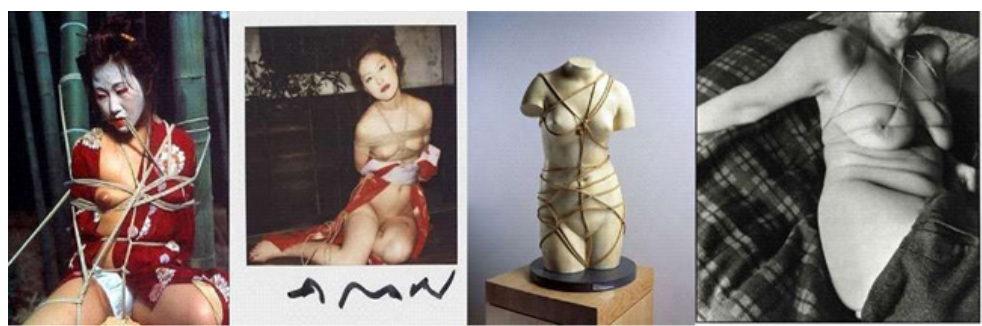

Figura 8. "Kioto" 1996 "Geisha Atada" Nobyoshi Araki

"Venus restaurada" Man Ray 1925 "Unie Atada" Hans Bellmer 1958. 

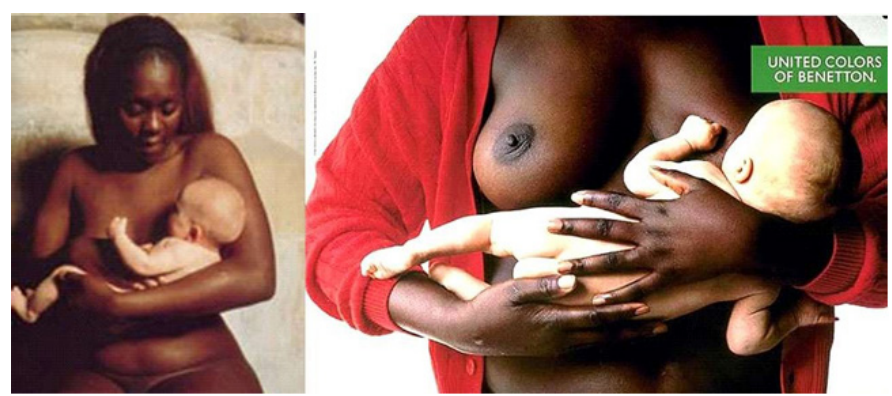

Figura 9. "Guiada" 1996. "Magdalena Arrepentda" Caravaggio 1596.

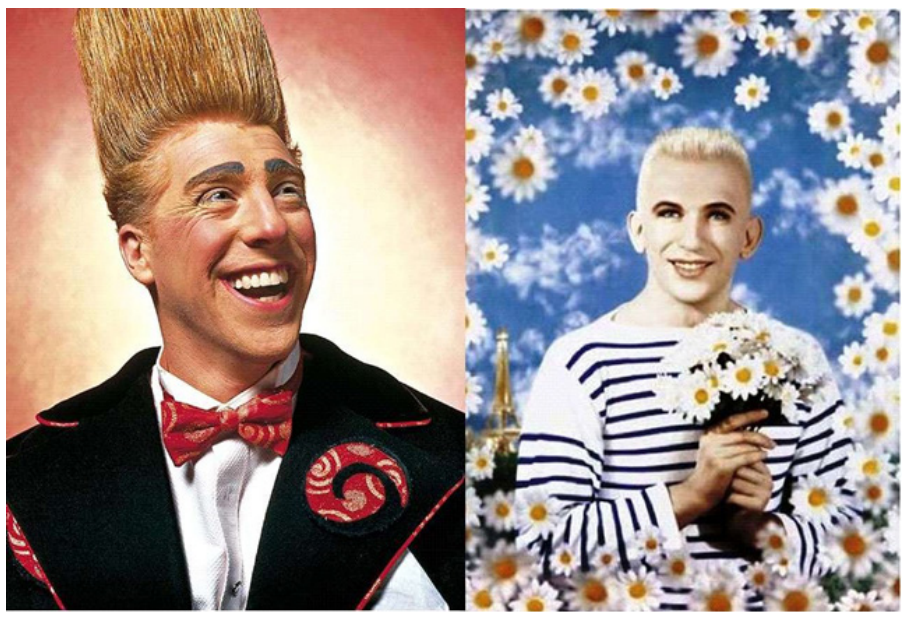

Figura 10. "Mujer y niño" 1996.

"Beneton" Oliverio Toscani 1990. 


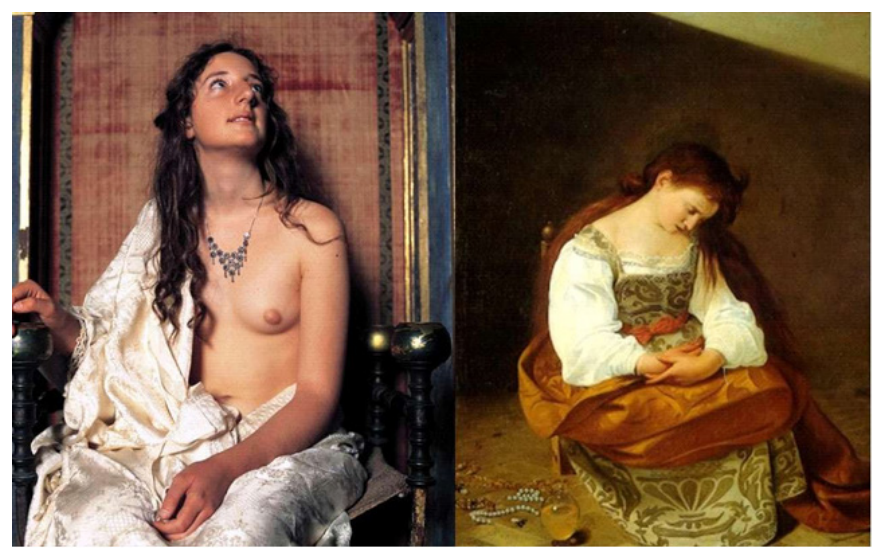

Figura 11. "Bello Nock” 2003. "Jean Paul Gauter" 1990. Pierre \& Gilles. 